\title{
Empreendedorismo moral no debate sobre sexualidade na escola: um estudo de fake news checadas pelo site E-farsas
}

\author{
Joseeldo da Silva Júnior (UFPB)* \\ https://orcid.org/0000-0002-3872-9425 \\ Francisco Vieira da Silva (UFERSA)** \\ https://orcid.org/0000-0003-4922-8826
}

\section{Resumo:}

Este estudo visa analisar discursivamente como as fake news sobre a educação brasileira se articulam com a moral conservadora para discursivizar o campo da sexualidade, pensando que, na contemporaneidade, há uma imensa circulação de dizeres falsos que contaminam o debate público e, neste caso em específico, o campo escolar. Tem-se que, no espaço das mídias sociais, uma parcela da sociedade tem corporificado um discurso contra a deterioração da infância, sob o alicerce de um empreendimento moral cristão. Dito isso, esse estudo é pautado pelo método "arquegeneológico", pensado a partir das noções de Michel Foucault, cuja contribuição teórica implicou na formação dos Estudos discursivos foucaultianos. 0 corpus é formado por três notícias falsas verificadas pela agência de checagem $E$-farsas, site especializado em descontruir narrativas falsas disseminadas nas mídias sociais. Metodologicamente, trata-se de uma pesquisa de natureza qualitativa, com viés interpretativo-descritivo. 0 movimento analítico permite observar, na produção discursiva das fake news, o funcionamento de uma moral religiosa que condena o modo como a sexualidade é tratada no ambiente escolar, pois este é configurado como um lugar potencialmente nocivo para a infância.

Palavras-chave: Discurso. Moral. Sexualidade. Fake News.

\section{Abstract:}

\section{Moral entrepreneurship in the debate on sexuality at school: a study of fake news checked by the website E-farces}

This study aims to analyze discursively how fake news about Brazilian education articulates with conservative morals to discursivize the field of sexuality, thinking that, in contemporary times, there is an immense circulation of false statements that contaminate the public debate and, in this specific case,

* Mestre em Linguística pela Universidade Federal da Paraíba (UFPB). E-mail: joseeldojr@gmail.com

** Docente Universidade Federal Rural do Semi-Árido (UFERSA). E-mail: francisco.vieiras@ufersa.edu.br 
the school field. It has to be said that, in the space of social media, a portion of society has embodied a discourse against the deterioration of childhood, underpinned by a Christian moral enterprise. That said, this study is guided by the "archeogeneological" method, thinking from the notions of Michel Foucault, whose theoretical contribution implied the formation of Foucault's discursive studies. The corpus consists of three fake news stories verified by the verification agency E-farsas, a site specializing in false narratives published on social media. Methodologically, it is a qualitative research, with an interpretive-descriptive bias. The analytical movement allows us to observe, in the discursive production of fake news, the functioning of a religious moral that condemns the way sexuality is treated in the school environment, as it is configured as a potentially harmful place for childhood.

Keywords: Discourse. Moral. Sexuality Fake News.

\section{Introdução}

O tema sexualidade ainda constitui um tabu na sociedade brasileira. No entanto, quando associado ao campo da educação e infância, o tema parece ser ainda mais incisivo. Foucault (2009, p. 09), em sua aula inaugural no Collége de France, assevera que a sexualidade é realmente a região "onde a grade é mais cerrada, onde os buracos negros se multiplicam". Olhando para o cotidiano, com foco no fenômeno contemporâneo das fake news, sobretudo aquelas que são pautadas pela sexualidade, constatamos que a fala de Foucault mostra-se bastante atual. Na era pós-verdade, como costumam falar alguns estudiosos da comunicação como Santaella (2018) ou Ferrari (2018), é comum e frequente depararmos-nos com uma miríade de fake news nas mídias sociais digitais.

Temos visto, ao longo dos últimos anos, mais precisamente após as eleições presidenciais americanas e o processo do Brexit (saída do Reino Unido da União Europeia), ambos em 2016, e pouco depois, em 2018, no período eleitoral brasileiro, uma excessiva difusão de conteúdo mentiroso, propiciando, na sociedade brasileira, um grande debate sobre os problemas advindos desse "vírus informativo". Delineando um pouco, este artificio político em que se tornaram as fake news tem sido usado para desferir ataques à educação brasileira, muitas vezes associadas à questão da infância, como pontuamos inicialmente. Isso ficou evidente no período de campanha eleitoral que legitimou Jair Bolsonaro à presidência da República, em 2018. Houve, naquele momento, uma campanha exaustiva para descaracterizar o ensino e a educação no Brasil, tendo como pano de fundo o fantasma da "ideologia de gênero" e a criação de dizeres sedimentados acerca do "kit gay" e da "mamadeira de piroca", os quais, conforme Almeida (2019), tiveram um papel decisivo na (i)legitimidade dos candidatos. 0 possível uso de robôs digitais (bots) para disseminar notícias falsas em conjunto com o funcionamento dos algoritmos digitais é uma associação preocupante que até hoje (2020) se arrasta no âmbito político-jurídico, conforme podemos observar na atuação Comissão Parlamentar de Inquérito (CPI) das fake news no Senado Federal.

O debate público, principalmente a partir de 2018, passou a ser em torno da noção da infância, que, para os que defendem a mitigação da "ideologia de gênero", estaria 
sendo desvirtuada por práticas promovidas por um governo de esquerda. Uma vastidão de notícias falsas produziu dizeres sobre a educação na infância, na maioria das vezes relacionados com cenas de teor sexual, promovendo, dessa forma, uma incitação nas mídias digitais à boa conduta das crianças, que deveriam ser protegidas do saber sexual empreendido pelas instituições educacionais. Em suas pesquisas, Foucault (2017) mostra que a criança, historicamente, deve ser investida da pureza, ser mantida distante de comportamentos que possam causar ideações sexuais nela. 0 autor chama atenção para a proteção do corpo das crianças a partir do século XVIII.

Por ser "objeto de preocupação e análise" e alvo de "vigilância e controle", segundo atesta Foucault (2017, p. 236), a sexualidade infantil foi cercada de tensões. Havia preocupação em relação ao corpo da criança, que, na esfera familiar, se tornou um jogo de luta entre os pais, promoventes frequentes de controle.

Os controles da masturbação praticamente começaram na Europa durante o século XVIII. Repentinamente, surge um pânico: os jovens se masturbam. Em nome deste medo foi instaurado sobre o corpo das crianças através das famílias, mas sem que elas fossem a sua origem - um controle, uma vigilância, uma objetivação da sexualidade com uma perseguição dos corpos. (FOUCAULT, 2017, p. 236).

Esse aparato repressivo em torno da autoerotizacação da infância percorreu e se perpetuou no século XIX, embora as técnicas de controle sempre fossem alvo de reformulações, pois o controle da sexualidade infantil estava fadado ao fracasso, conforme aponta Foucault, pois o dever dos pais era proteger as crianças dos "hábitos solitários", ou seja, da prática da masturbação. Houve uma verdadeira mobilização, a fim de blindar a criança em torno do sexo, suscitando segredos em torno disso. Se, por um descuido o perigo estivesse à espreita, eram "instalados dispositivos de vigilância, estabelecidas armadilhas para forçar confissões, impostos discursos inesgotáveis e corretivos" (FOUCAULT, 2018, p. 42).

Alertas aos pais e professores eram emitidos, conflagrando a ideia de que todas as crianças possuíam atitudes suspeitas e, portanto, reprováveis aos olhos dos vigilantes morais. Enquanto vigilantes, se houvesse fuga de diretriz, a medida imposta era de culpa a si mesmos, por agir com descuido. 0 poder repressivo sobre as crianças, no entanto, quando não exitoso, resultava em uma "revolta do corpo sexual" contra essa ofensiva. Segundo explica Foucault (2017, p. 147), o outro poder responde "através de uma exploração econômica (e talvez ideológica) da erotização", como o consumo de filmes pornográficos. Há aí um novo investimento em contraponto às medidas de repressão do corpo: não mais um investimento na forma de controle-repressão, mas, agora, na forma de controle-estimulação. Daí, a ideia de o poder ser produtivo.

Partindo dessas reflexões, o propósito deste estudo é investigar como as fake news sobre a educação brasileira articulam-se com a moral cristã para discursivizar o campo da sexualidade. Ora, como dito inicialmente, as fake news ganharam notoriedade no contexto das eleições presidenciais no Brasil, mas, mesmo antes da disputa eleitoral, havia a propagação destes informativos virtuais de modo a atacar a educação no Brasil e descontextualizar o ensino sobre sexualidade no âmbito escolar. A criança, nesse sentido, é usada como instrumento de moralização da sociedade, ao tomá-la como objeto de defesa aos interesses pessoais e 
ideológicos de determinado grupo político. Esse grupo fortalece-se em função do crescimento vertiginoso de políticos vinculados aos movimentos neopentecostais e a setores da Igreja Católica que impulsionam uma agenda conservadora e, por isso, demonizam qualquer menção à sexualidade no contexto da escola.

Metodologicamente, este trabalho inscreve-se no arcabouço teórico da chamada "arqueogeneaologia", proposta a partir das ideias do filósofo francês Michel Foucault, que contribuiu para a promoção dos estudos discursivos foucaultianos em território brasileiro. Nesta pesquisa, de caráter qualitativo, com viés interpretativo-descritivo, propomos analisar três notícias sobre sexualidade e educação, verificadas pela agência de checagem E-farsas, site especializado em descontruir narrativas falsas disseminadas nas mídias sociais.

Em relação à estrutura deste artigo, o primeiro tópico discute a noção de moral pensada por Foucault e como ela se articula com as fake news, a partir da análise da notícia falsa sobre o chamado "Kit Gay". Na seção seguinte, analisamos duas notícias falsas checadas pelo E-farsas, a partir das reflexões desenroladas no tópico anterior. Finalmente, o último tópico cuida de tecer algumas considerações de natureza conclusiva para este estudo.

\section{Empreendedorismo moral na pauta da sexualidade}

A sexualidade, durante muito tempo na história, esteve interditada, explica Foucault (2006), afirmando que, graças a Freud, e a partir dele, além da contribuição dos movimentos sociais e culturais, a sexualidade passou a ser discursivizada sob modos específicos. $\mathrm{O}$ autor francês mostra que, aos poucos, o tema começou a ser publicamente discutido, uma vez que, em outros tempos, a sexualidade foi tomada por uma moral burguesa e uma moral cristã, que "haviam impedido o Ocidente de interessar-se pela sexualidade" (FOUCAULT, 2006, p. 62). 0 surgimento do cristianismo propiciou certa interdição da sexualidade no Ocidente, mas não significa dizer que não se falava sobre o sexo e não se produziam verdades sobre ele.

A burguesia, que se encontrava em uma posição de hegemonia, mantendo um poderio econômico e cultural, na esteira do pensamento cristão, agiu de forma semelhante na pauta da sexualidade, ou seja, através de um empreendedorismo moral, ergueuse contra a sexualidade. Isso durou cerca de três séculos - de XVI à XIX, quando as discussões de Freud iniciaram. Esse pensamento a respeito da moral burguesa e cristã é criticado por Foucault, que, para ele, não se tratava apenas de uma interdição e recusa, mas, sim, a instauração de um mecanismo de poder que possibilitou pensar a sexualidade no Ocidente. 0 filósofo francês chama de poder pastoral, poder pelo qual as condutas são guiadas, tendo como figura central um pastor. De acordo com Foucault (2006), trata-se de uma tecnologia de poder que tem como propósito derradeiro a salvação individual no outro mundo e que cuida não somente de uma comunidade como um todo, mas de todos os indivíduos de maneira particular e implica uma determinada direção de consciência.

Foucault não pretendeu criar uma história da sexualidade baseada em preceitos morais, apesar de não os ignorar. No entanto, de acordo com Candiotto (2013, p. 220), sua preocupação centrava-se na "constituição ética do sujeito, no sentido de perguntar pela relação singular que podemos criar em relação a nós mesmos diante dos códigos 
morais que nos são propostos culturalmente e dos princípios normativos que tendem a direcionar nosso agir".

Foucault (1984) estava interessado em saber o motivo pelo qual o campo da sexualidade era revestido por uma preocupação moral, bem como lhe interessava igualmente o porquê de haver, em algumas sociedades, maior atenção à sexualidade do que qualquer outra coisa. 0 cerne da questão centrava-se no movimento que se deu entre a Antiguidade e a época moderna, na figura do Cristianismo, emergindo disso os seguintes problemas:

por que o comportamento sexual, por que as atividades e os prazeres que dele decorrem são objeto de uma preocupação moral? Por que esse cuidado ético que, pelo menos em certos momentos, em algumas sociedades ou em certos grupos, parece mais importante do que a atenção moral dirigida a outros domínios, no entanto essenciais para a vida individual ou coletiva, como as condutas alimentares ou o cumprimento dos deveres cívicos? (FOUCAULT, 2006, p. 198)

Uma das respostas para tais questões deve-se, segundo o filósofo, às interdições que cerceiam a sexualidade, cujas transgressões seriam consideradas um desatino. No entanto, o pensador francês não se restringe a isso, uma vez que a preocupação ética não esteve sempre relacionada ao sistema de interdição, que é tomada apenas como um ponto em particular. Na verdade, trata-se de suscitar uma problematização moral, sobre a qual perfazem as seguintes questões: "por que e sob que forma a atividade sexual foi constituída como domínio moral? Por que esse cuidado ético tão insistente, apesar de variável em suas formas e em sua intensidade? Por que essa "problematização"?" (FOUCAULT, 2006, p. 198)

A investigação do filósofo francês focava em descobrir como um indivíduo, a partir das práticas de si, subjetiva-se, mediante preceitos éticos e morais. A moral pensada pelo autor, portanto, está relacionada "com os sentidos de ética; como uma relação que os indivíduos têm com eles mesmos e as diversas práticas de liberdade" (FARIAS, 2015, p. 145). Nesse sentido, é através de práticas denominadas de "artes da existência" que o indivíduo se molda, determinando para si não apenas regras de conduta, de comportamento, mas também uma busca em "transformar-se, modificar-se em seu ser singular". (FOUCAULT, 2006, p. 198).

Foucault (2006) mostra uma oposição entre uma moral regida pela Igreja e a pastoral cristã, de um lado, e a moral na Antiguidade, por outro lado. Para a instituição cristã, havia uma moral cujas regras eram coercitivas, alcançando a todos. Ou seja, todo o indivíduo cristão deveria se situar a partir de uma cartilha única. Já no pensamento grego, a presença da austeridade não era compartilhada unicamente por todos; não era autoritária e imposta de forma geral aos indivíduos como um todo. Não se pode dizer, contudo, que a "moral cristã do sexo era, de certa forma, 'pré-formada' no pensamento antigo" (FOUCAULT, 2006, p. 208). Assim, é preciso entender que muito precocemente formou-se, na reflexão moral da Antiguidade, "[...] uma temática da austeridade sexual, em torno e a respeito da vida do corpo, da instituição do casamento, das relações entre homens e da existência da sabedoria". (FOUCAULT, 2006, p. 208).

Um ponto a notar nas práticas morais é que, onde havia maior controle, mais coerções, onde as proibições estavam mais pontuais, é que foi desenvolvido forte rigor em relação às austeridades. Isso não se estendia, no entanto, aos modelos sociais da Antiguidade. Um exemplo: as mulheres deveriam se submeter aos caprichos dos homens. 
Apesar dessa submissão, essa não era uma moral destinada às mulheres, mas, sim, aos homens, embora elas fossem predestinadas à submissão, pois apareciam como objetos que tinham como função era ensinar, educar, vigiar. Trata-se, com efeito, de uma moral viril, ensinada por homens e dirigidas aos homens. As mulheres não criavam as condutas, isso era feito pelos homens; por isso, uma moral para eles.

Diz Foucault (2006, p. 209) que a mulher "não se dirige aos homens a propósito de condutas que poderiam decorrer de algumas interdições reconhecidas por todos e solenemente lembradas nos códigos, nos costumes ou nas prescrições religiosas" mas, sim, por que há um "propósito de condutas nas quais justamente eles devem fazer uso de seu direito, de seu poder".

Dito isso, Foucault (2006) procura entender o motivo pelo qual o comportamento sexual foi pensando como domínio de experiência moral. Para responder a isso, ele compreende a moral a partir de duas vertentes. Uma, entendida "como um conjunto de valores e de regras de conduta que são propostas aos indivíduos e aos grupos por meio de diversos aparelhos prescritivos, como podem ser a família, as instituições educativas, as Igrejas etc". Outra, avaliada por um "comportamento real dos indivíduos em sua relação com as regras e valores que lhes são propostos" (FOUCAULT, 2006 p. 211).

A respeito desses aparelhos prescritivos, Foucault (2006) mostra que eles instituem a criação de "códigos morais", ou seja, propõem regras de condutas. Pensando a respeito destes aparelhos formadores de condutas, podemos reconhecer na mídia um grande mediador potencial de sistema prescritivo, uma vez que ela, sendo uma produtora de verdades, estabelece-se como uma reguladora moral. Ela pode guiar condutas, impulsionar com- portamentos. Pensemos nas mídias sociais, por exemplo, há, nestas, uma circulação pletórica de imagens e textos reflexivos, religiosos, morais, cujos elementos "pretendem estabelecer regras, dar opiniões, conselhos de como se conduzir de modo adequado" (FOUCAULT, 2006, p. 200). Tem-se, com isso, o propósito de fazer com que os indivíduos interroguem a si mesmos, sua própria conduta, de modo a vigiá-la, reconstituí-la ou moldá-la enquanto sujeito ético. Trata-se, portanto, de instituir uma prática de si.

Posto isso, os sujeitos os quais se ligam às regras e valores que lhes são propostos, submetem-se a procedimentos de condutas, "pela qual obedecem ou resistem a uma interdição ou a uma prescrição, pela qual respeitam ou negligenciam um conjunto de valores" (FOUCAULT, 2006, p. 211). Esse ponto da moral determina como e de qual modo o sujeito conduz-se em relação a um sistema prescritivo, dado uma cultura a qual um ou outro esteja inserido. Foucault chama esse procedimento de "moralidade dos comportamentos".

Desse modo, as regras que ditam como "conduzir-se", ou seja, o modo como se deve constituir a si mesmo como um sujeito moral, estão em ação conforme "elementos prescritivos que constituem o código" (FOUCAULT, 2006, p. 211). Subsistem inúmeras maneiras de o indivíduo se conduzir moralmente, "diferentes maneiras para o indivíduo ao agir, não operar simplesmente como agente, mas sim como sujeito moral dessa ação" (FOUCAULT, 2006, p. 211). Ou seja, o indivíduo participa ativamente da atividade moral que exerce, colocando-se como moralista, embora não seja pronunciado isso. Ao se comportar como ativista moral, o indivíduo desenvolve o que Foucault (2006) chama de "determinação da substância ética", isto quer dizer que um aspecto de si mesmo 
se constitui como um produto de sua conduta moral. É dessa forma que o indivíduo irá respeitar determinados padrões que, para si, são éticos, a fim de que não recaia numa interdição, por exemplo.

Para além disso, há também os modos de sujeição, a partir dos quais os indivíduos relacionam-se com regras específicas e se reconhecem na obrigação de executá-las. Podemos enxergar aí a preocupação de sujeitos em relação à educação de seus filhos, em protegê-los do ensino da sexualidade, o qual seria necessariamente nocivo e pecaminoso. Tais sujeitos veem-se na posição de resguardar a criança, de modo que não haja contato com temas que a coloque em risco, seguindo uma dada visão de mundo. Para citar um exemplo, tomemos a fake news que trata da obra "Aparelho sexual e cia.", apresentado pelo então candidato à presidência da República, Jair Bolsonaro, durante entrevista ao programa Jornal Nacional, da TV Globo, em agosto de 2018. 0 livro foi mostrado como sendo parte do chamado "kit gay", que também, segundo o candidato, foi lançado no "9o Seminário LGBT infantil", realizado no Congresso Nacional.

Esta narrativa de Bolsonaro foi verificada pela agência de checagem E-farsas, a qual constatou que o evento mencionado pelo então candidato jamais existiu. Na verdade, ocorreu no Congresso Nacional o "9o Seminário LGBT", com o tema infância e sexualidade, organizado pelo deputado federal Jean Wyllys (PSOL), ex-coordenador da Frente Parlamentar Mista pela Cidadania LGBT. De acordo com o E-farsas, o evento teve como objetivo a discussão em torno da proteção da infância e do reconhecimento da diversidade sexual. Porém, o livro não foi lançado nem distribuído. Não obstante, de acordo com um estudo da Organização Avaaz, 98, 21\% dos eleitores de Bolsonaro foram expostos a uma ou mais notícias falsas durante a corrida presidencial de 2018 e cerca de 89,77\% deles acreditaram que se tratavam de fatos reais ${ }^{1}$. Conforme pontuam Caldas e Caldas (2019, p. 209), “[...] produzem-se fake news intentando desarmonia e conflito entre pessoas e grupos. Ademais, quando esse tipo de notícia é disseminado, é pouco provável que se reverta o dano causado".

Figura 1: Checagem da notícia sobre o "kit gay"

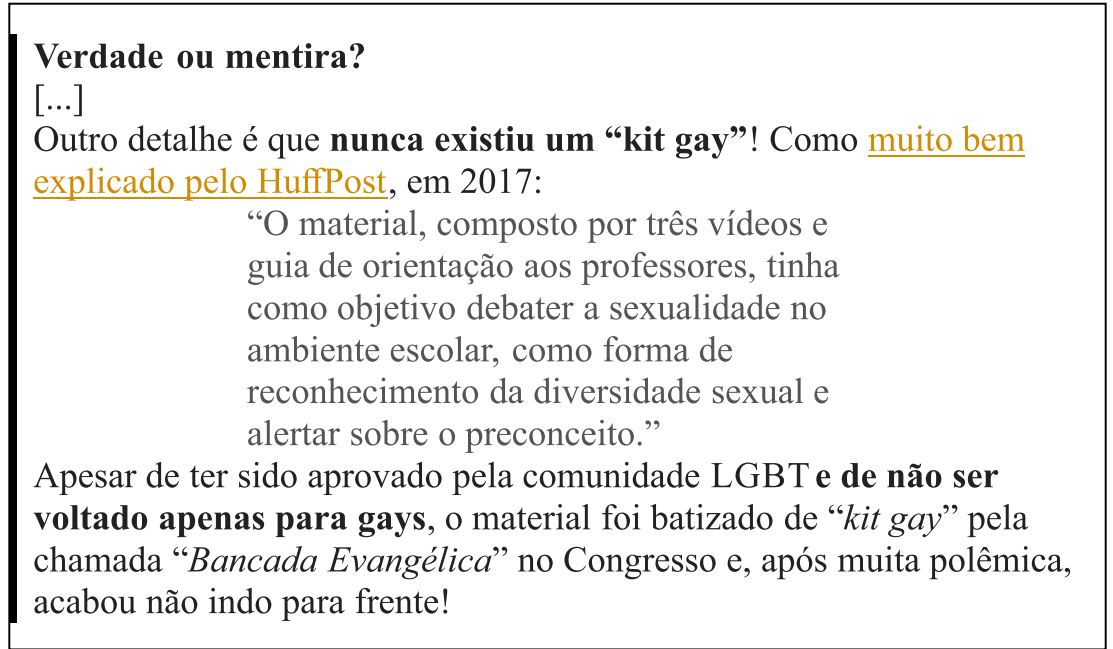

Fonte: E-farsas, 2019.

1 Disponível em: <https://valor.globo.com/politica/noticia/2018/11/02/estudo-diz-que-90-dos -eleitores-de-bolsonaro-acreditaram-em-fakenews.ghtml>. Acesso em: 10 maio de 2020. 
Na verificação apontada acima, o site $E$ farsas esclarece que "nunca existiu um kit gay", conforme alertou Jair Bolsonaro. 0 material do Ministério da Educação (MEC), parte do Programa Brasil sem Homofobia, constituía um guia de orientação para os professores e uma série de três vídeos com o propósito de debater acerca da sexualidade entre os jovens. Alvo de críticas, o material recebeu o apelido de "kit gay" por deputados religiosos e, consequentemente, foi retirado de circulação. Referindo-se ao livro "Aparelho sexual e cia.", o E-farsas destaca que, desde 2013, o MEC informa que tal obra não foi distribuída nas escolas públicas, que "não consta no Programa Nacional do Livro Didático/PNLD e no Programa Nacional Biblioteca da Escola/PNBE" (EFARSAS, $2019 \mathrm{~s} / \mathrm{p}$ ).

Como a constituição desta fake news, houve a descaracterização da imagem do também candidato à presidência da República Fernanda Haddad, do Partido dos Trabalhadores (PT), que, na época do episódio da primeira polêmica acerca do "kit gay", esteve à frente do Ministério da Educação (MEC), na função de ministro. No entanto, apesar da retomada da narrativa do "kit gay" possuir propósitos eleitorais, ao focar na educação, tem-se como empenho manifaturar um alvoroço midiático, justificado por uma escalada moral nos debates que dizem respeito à sexualidade. É possível levantar, a partir disso, que os sujeitos que ratificam essa fake news buscam se insuflar contra um suposto atentado à inocência infantil. Diz-se que o "Kit Gay" ensinaria às crianças sobre sexo e mudaria suas condutas, quando, na realidade, o livro tratado destina-se à orientação sexual de alunos entre onze e quinze anos de idade.

Os defensores da boa conduta se reerguem pautados numa moral cristã, que, por sua vez, também rege esta fake news, desde a sua fabricação até o compartilhamento nas mídias sociais digitais. A "moralidade de comportamento" que se apoia revelase, portanto, na postura que possuem ao repassar adiante a mentira virtual. Conforme Foucault esclarece, há certas formas de "elaboração do trabalho ético realizado sobre si mesmo, não apenas para tornar seu comportamento conforme a uma regra dada, mas sim para tentar transformar a si mesmo em sujeito moral de sua conduta". A regra, neste caso, seria os postulados cristãos, segundo os quais deve-se guardar os segredos do sexo, tal como Foucault (2016) mostra na anedota do elefante ${ }^{2}$, o regramento em relação ao acasalamento, que deveria se estender para a vida de um casal de homem e mulher. Ao remetermos a um certo pânico moral (MISKOLCI, 2007), provocado pela narrativa do "kit gay", vemos nisso uma vontade de que seja confinado o segredo do sexo, que deve ser mantido exclusivamente no espaço privado. Com isso, constrói-se um modelo de sujeito moral, que dissemina fake news, a fim de mostrar-se um defensor dos bons costumes.

Dessa forma, não se pode ferir ou transpassar os ensinamentos cristãos, sendo preciso cada vez mais interiorizar aspectos essenciais para uma vida moral, os quais segundo Foucault (2016, p. 29), deve-se aprender a "como se comportar, como se

2 Para ilustrar como as relações conjugais se revestiam de pudor e moralismo no século XVIII, Foucault, na obra Subjetividade e Verdade, recorre à anedota do elefante, de São Francisco de Sales, em uma das suas aulas, no Collége de France. 0 autor evidencia que o elefante amava unicamente a uma elefanta com a qual permanecia até o fim da vida. No momento da cópula, havia um regramento que resguardava este segredo, que, sob nenhuma hipótese, era conhecido pelo homem. Assim, com todo este revestimento moral, tentava-se aplicar a mesma conduta dos elefantes para a vida matrimonial. 
apresentar, como fazer para adquirir determinada aptidão, que tipo de relação se deve estabelecer com os outros, como aparecer em público, como se portar de modo decente etc". Mas não somente. É preciso, também, na prática de uma ação moral, ainda de acordo com Foucault (2006, p. 213), constituir uma conduta moral que conduza o indivíduo não simplesmente a ações sempre de acordo com valores e regras, mas também a um certo modo de ser", caracterizando, assim, o sujeito moral. Vejamos que, antes de se tornar alvo de checagem, a fake news sobre o "kit gay" reverberou através do candidato à presidência e, posteriormente, passada como verdadeira por outros eleitores.
A atitude em encaminhar e compartilhar em sites de redes sociais, por exemplo, revela a conduta do sujeito, em seu profundo medo e desespero moral. É marcado também um posicionamento político, de viés extremista, ao ser amparado por discursos autoritários.

\section{"É isso que você quer que seu filho aprenda em sala de aula?"}

Neste tópico, analisaremos mais duas fake news que tratam sobre a sexualidade e a educação as quais foram checadas pelo site E-farsas. Vejamos a primeira delas que foi veiculada numa página do Facebook com direcionamento político de direita.

Figura 2: Fake news de professora ministrando aula sobre sexualidade

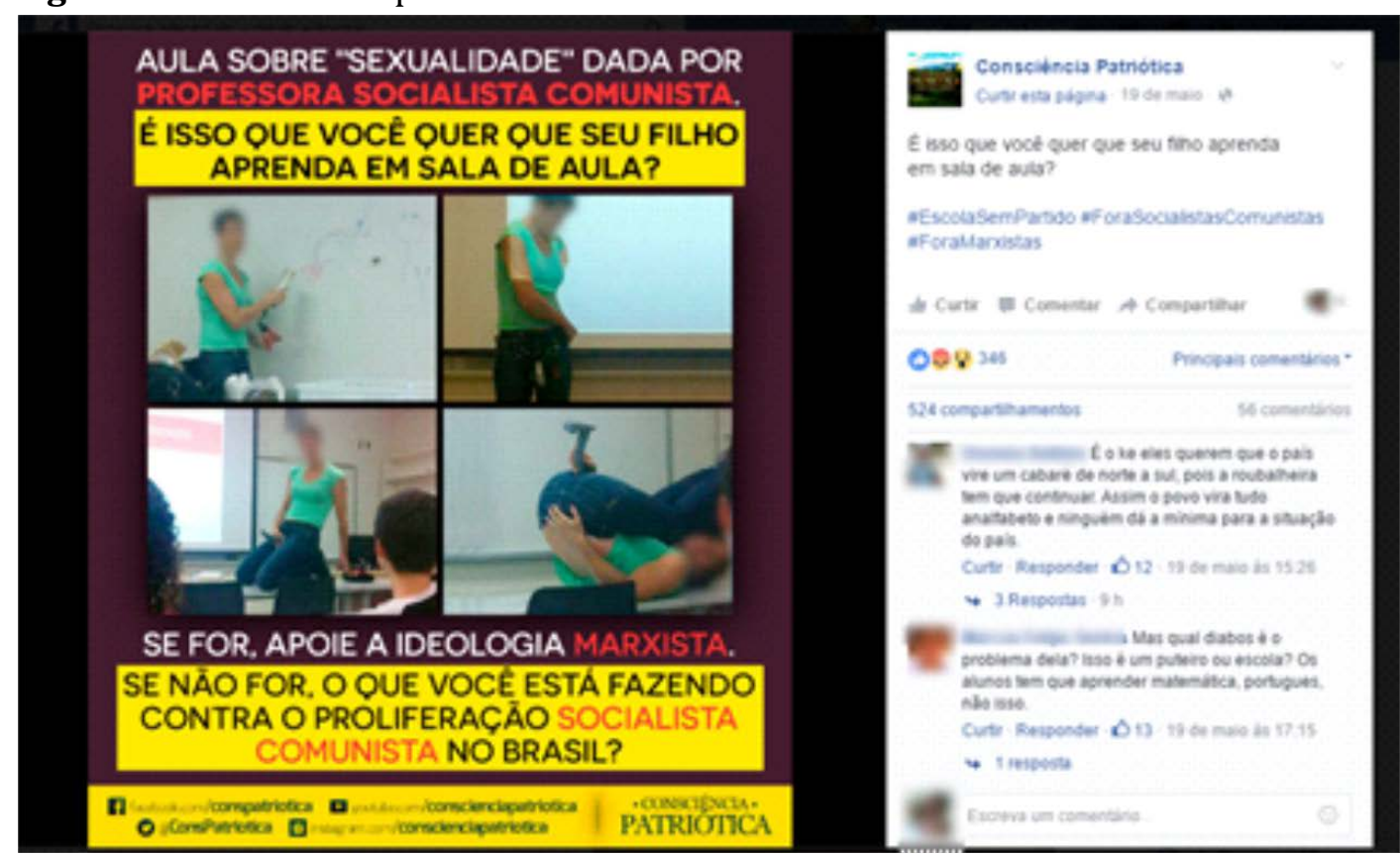

Fonte: E-farsas.com, 2019

$\mathrm{Na}$ figura, vemos uma montagem de uma mulher em uma possível sala de aula, mostrada em blocos de imagens fazendo performances. A imagem foi distribuída pela web, em tom alarmista, chamando a atenção para o fato de uma professora, considerada socialista e comunista, estar proferindo aulas sobre sexualidade para crianças e mostrando, na prática, como seria o ato sexual. 0 uso das aspas sobre o termo sexualidade demonstra que o posicionamento discursivo presente na postagem desconfia de como seria a abordagem sobre essa temática na escola. Ou seja, seria um tratamento pornográfico, erótico e impróprio para as crianças. 0 questionamento feito pela postagem caminha nessa mesma direção: é preciso minar a atuação 
de professores marxistas, comunistas e socialistas, pois estes são essencialmente imprudentes e temeráveis e, por isso, é necessário apoiar a derrubada dessas condutas. Nisso repousa o emprego da hashtag \#Escolasempartido. 0 uso da cor vermelha remete nos termos comunista e socialista, por meio de um domínio de memória, o perigo que advém da esquerda, do espectro de ideologias danosas para a moral cristã. A defesa de uma escola apartidária significa a exclusão de posicionamentos políticos que se alinham à esquerda, principalmente.

A imagem foi publicada na página ${ }^{3}$ do Facebook intitulada "Consciência Patriótica". Obteve mais de 500 compartilhamentos e mais 300 reações, além de dezenas comentários. Uma vez reverberada na web, a fake news ganhou a verificação do checador E-farsas. A notícia publicada leva o seguinte o título: "Professora ensinando como usar brinquedos eróticos?". Reproduzimos abaixo trecho da materialidade presente no corpo do material inspecionado.

Como podemos visualizar através das imagens, existe uma ressignificação dos fatos outrora construídos e reproduzidos no espaço virtual. 0 site E-farsas aponta que as informações presentes na imagem montada não são verdadeiras e que, portanto, caracteriza-se por ser uma fake news. A agência de checagem trata de analisar uma notícia falsa que reverberou nas mídias sociais, de modo a restabelecer a verdade acerca das informações falsas propagadas internet afora. Nesta fake news específica, vemos mais uma vez a tentativa de associar o ensino brasileiro a um conjunto de práticas "imorais". Para isso, as imagens escolhidas pro-

3 Principalmente no Facebook, há a existência de inúmeras páginas com tendência nacionalista. Muitas delas se opõem às pautas progressistas e estão direcionadas com o discurso político encabeçado pelo atual presidente Jair Bolsonaro. põem-se a causar escândalo e convencer os pais de que é preciso se voltar contra essa perversão das subjetividades escolares.

\section{Figura 3: Checagem de fake news}

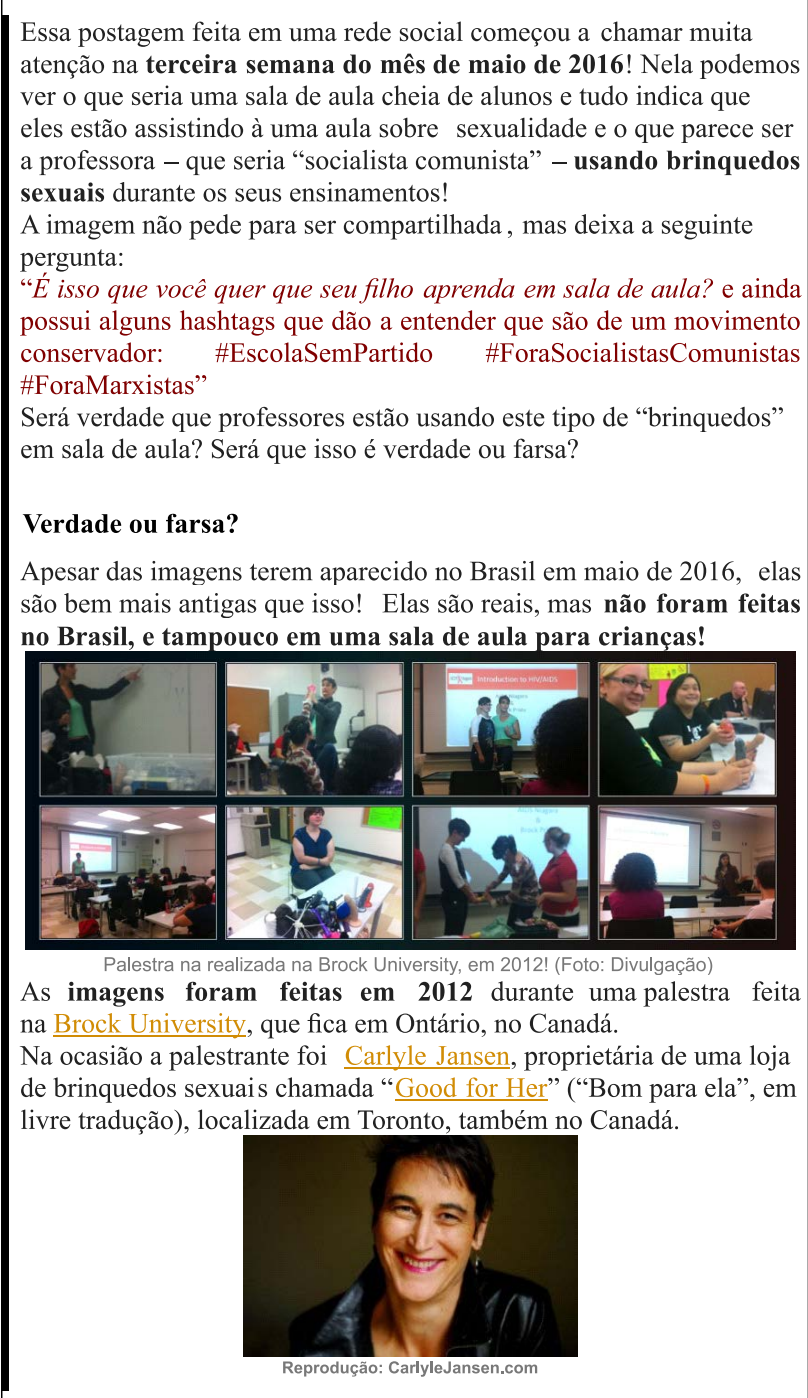

Fonte: E-farsas, 2019.

Existem, tal como se nota na montagem, performances sexuais que não condizem com o grau de instruções das crianças, considerando o contexto da fake news. A respeito do corpo, Foucault (2017) admite que nele ocorre investimento de poder, suscetível de consequências, como o engendramento de normas éticas sobre os quais este corpo deve ser submetido. Nesse sentido, ao produzir gestos sexuais em sala, a imagem da professora é revestida de um discurso moral, rompendo com os 
códigos de conduta que uma sala de aula, em tese, deve possuir.

Ao observar o enunciado verbo-visual como um todo, deduz-se que houve uma seleção de determinadas imagens publicadas em detrimentos de outras, a fim de que pudesse produzir um efeito com sentido meramente pornográfico. Ao ser associado ao discurso da educação, as imagens reverberam como um atentado à boa conduta escolar, sobretudo, por haver indicativos que implicarão na defesa da criança, que, para o contexto da sala de aula, torna-se abominável e impróprio. Por isso, chama-se a atenção para os pais e responsáveis pela postura nada exemplar da suposta professora.

A sala de aula, como parte inalienável da instituição disciplinar que é a escola, deve cumprir seu intento de docilizar os corpos. Muito embora estes corpos possam se aperfeiçoar e ser transformar, eles estão sujeitos a proibições, limitações ou obrigações, conforme atesta Foucault (2014). As disciplinas instituem "métodos que permitem o controle minucioso do corpo, que realizam a sujeição constante de suas forças e lhes impõem uma relação de docilidade-utilidade" (FOUCAULT, 2014, p. 135).

Enquanto instituição disciplinar, a escola pauta-se em políticas de coerção dos corpos, por meio de manipulações minimamente calculadas dos gestos e dos comportamentos. Assim, transgredir estes preceitos, digamos, tradicionais, faz resultar olhares preconceituosos, como ocorrido na performance acima tratada. Vale dizer, ainda, que a descontextualização das imagens, a nosso ver, é essencial para cumprir com a tarefa de causar pânico moral, ou seja, criar alarde sobre falsa desvirtuação da infância. A imagem, propositalmente, estampa enunciados chamativos, com a finalidade de causar alvoroço e pânico. De acordo com Brandão e Lopes (2018, p.
115-116), “[...] o alarde promovido em torno dos perigos que a inclusão de gênero e sexualidade poderiam engendrar, na medida em que 'implodem' os modelos rígidos, 'naturais' de gênero, sexualidade, casamento e família”.

A fake news checada, mesmo que não trate especificamente do ensino da sexualidade para crianças, trava o debate acerca da moralização do assunto na política brasileira encarnada na figura da professora. A criança, tal como Foucault (2017) salienta, deve ocupar um espaço sacro, excluindo-se de temas que versam sobre o seu próprio corpo ou no corpo adulto. No âmbito escolar, o ensino-aprendizagem deve ser limitado às matérias tradicionais, pois esta é a vontade de verdade que deve imperar, como atesta a indagação inicial feita na publicação da fake news em comento: "É isso que você quer que se seu filho aprenda em sala de aula?"

O E-farsas, ao promover uma vontade de verdade, reconstitui os fatos e confere o status de verdadeiro à checagem que realiza. $\mathrm{A}$ mulher em sala não mais ocupa a posição de professora, pois é recolocada na posição de palestrante, e sala de aula não se enquadra em um espaço brasileiro, mas, sim, americano. Os alunos, enfim, não são crianças. Todo esse movimento atesta o caráter moral da publicação além de reestabelecer a realidade dos acontecimentos.

Em mais um exemplo de como há uma postura moral que circunscreve o discurso sobre a sexualidade no âmbito escolar, vemos na próxima notícia verificada a informação de que o então deputado federal Jean Wyllys ${ }^{4}$ e a cantora Pabllo Vittar

4 O agora ex-deputado afirmou em entrevista que somente no período eleitoral de 2018 conseguiu retirar judicialmente 1 milhão de compartilhamentos difamatórios sobre ele nas redes sociais. Disponível em: <https://observatoriog.bol.uol. com.br/entrevistas/2019/09/jean-wyllys-falasobre-processos-vencidos-e-a-luta-contra-fakenews>. Acesso em: 11 maio de 2020. 
estariam preparando visitas pelas escolas públicas brasileiras. Na chamada consta o seguinte título: "Jean Wyllys e Pabllo Vittar farão turnê pelas escolas pra falar sobre diversidade?". No corpo da notícia, é informado que as duas personalidades iriam ensinar sobre diversidade sexual para crianças.

Figura 4: Jean Wyllys e Pabllo Vittar farão turnês pelas escolas

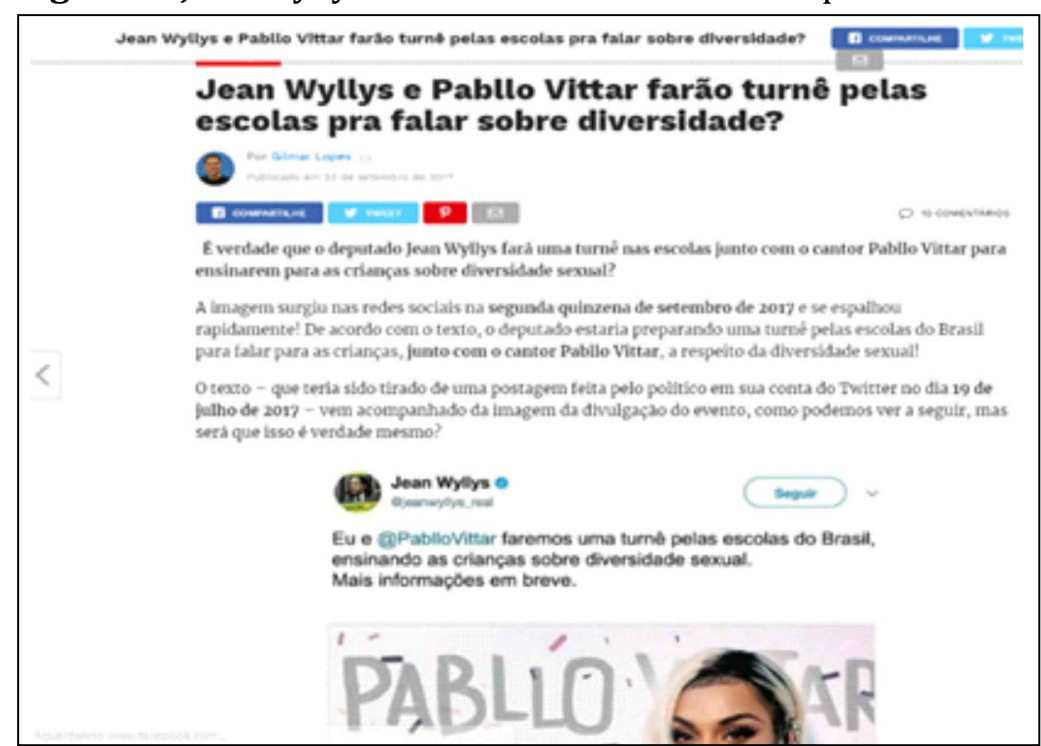

Fonte: E-farsas.com, 2019

A notícia foi baseada em uma postagem supostamente publicada no Twitter por Jean Wyllys, em que é feita a divulgação do evento. 0 conteúdo presente na publicação do tweet, no entanto, é falsa, conforme verificou o E-farsas, apontando que a imagem do cartaz sofreu edição. Trata-se de uma montagem produzida a partir de outro cartaz, porém destinado à publicidade de um programa de TV. Na figura abaixo, apresentamos a imagem original e o tweet fabricado contendo a informação falsa.

Figura 5 e Figura 6: Cartaz original de Pabblo Vittar e a publicação modificada

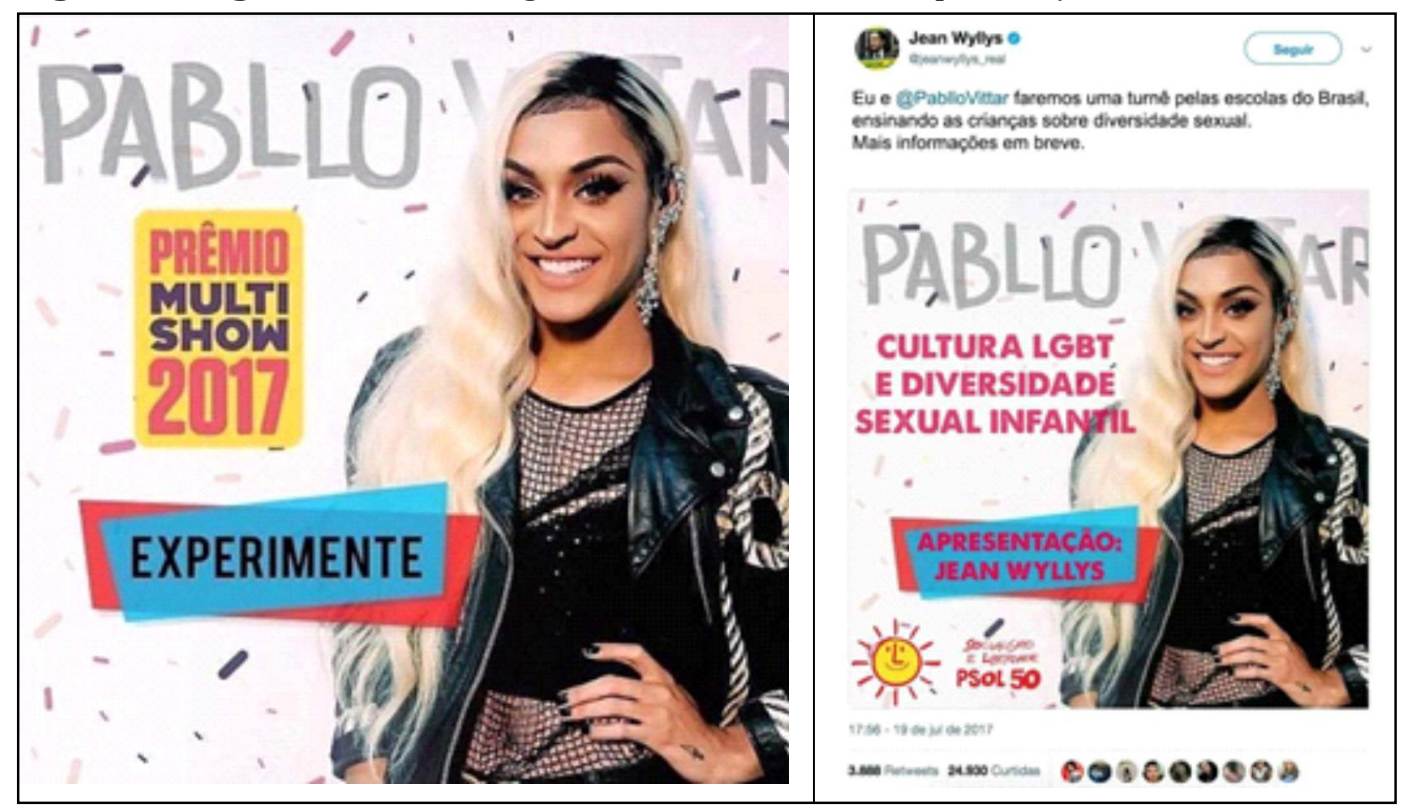

Fonte: E-farsas.com, 2019 
A tentativa de vincular Jean Wyllys e Pabllo Vittar ao contexto escolar infantil parte de um movimento organizado com a finalidade de desqualificar o debate acerca da sexualidade. Tanto Jean quanto Pabblo são assumidamente homossexuais. Logo, o contato deles com a cultura infantil no ambiente educacional pressupõe a ideia de que ambos iriam desvirtuar as crianças brasileiras, perturbando a inocência destas. Mas não somente. Pabllo Vitttar é uma cantora drag, enquanto Jean Wyllys é ex-deputado federal, gay e militante dos direitos humanos. Os dois, portanto, num país conservador como o Brasil, evidenciam tensões no leque de diversidades, cuja visibilidade incomoda. Wyllys era o deputado ex-BBB que supostamente condenava a Bíblia e que levantaria a bandeira de uma ditadura gayzista, Pabllo, ao desbotar o binarismo entre o masculino e o feminino, é concebido como um monstro moral. A homossexualidade, conforme mostra Foucault (2017, p. 396) é configurada como "uma prática sexual que, enquanto tal, é combatida, barrada, desqualificada" e as figuras de ambos são usadas como elementos de repulsa. 0 termo turnê remete-nos ao show, às performances de gênero assinaladas pelo glamour das divas do pop. Disso residiria o pavor: as crianças frente a um estilo de vida desviante e, portanto, pautado noutra moral que deve ser condenada. 0 símbolo do $\mathrm{PSOL}^{5}$ denota o alinhamento político dessa prática e corrobora para um desejo de criminalização dos movimentos de esquerda.

A implicância em montar uma narrativa na qual haja protagonistas homossexuais como palestrantes para crianças diz mais respeito ao incômodo pelo fato de ambos serem homossexuais do que pela perturbação provocada pela assistência a um ato se-

5 Partido Socialismo e Liberdade. xual. Como diz Foucault (1981, p. 02), “imaginar um ato sexual que não seja conforme a lei ou a natureza, não é isso que inquieta as pessoas. Mas que indivíduos comecem a se amar: aí está o problema". Certamente pode ser um ponto de vista, porém o fato de ambos serem "anormais" amplia o caráter abjeto que aparece de forma sorrateira nesta fake news. De acordo com Machado (2018), os cristãos defendem uma leitura a-histórica da Bíblia e nutrem uma visão heteronormativa e patriarcal da sociedade e, portanto, a presença de sujeitos que fogem a essa norma não são desejadas.

Ao tratar especificamente dos desejos, entendendo-o como sendo uma prática da sexualidade, a constituição de "novas formas de relações, novas formas de amor e novas formas de criação" (FOUCAULT, 2004, p. 260) possibilitam outras condutas sexuais, como a homossexualidade, que, enquanto objeto da sexualidade, trata-se de uma criação do desejo. Ela "se inscreve na necessidade, para nós hoje, de criar uma nova vida cultural, sob a condução de nossas escolhas" (FOUCAULT, 2004, p. 261. A presença de um homem gay e uma drag queen em debates públicos para crianças é, portanto, uma condição inaceitável, intolerável e que deve ser expurgada pelos "cidadãos de bem", autointitulados como defensores da família. Tem-se, nas palavras de Miskolci (2018, p. 10), “[...] um campo discursivo de ação que podemos reconhecer como unindo imaginariamente uma suposta ameaça de retorno do comunismo ao pensamento acadêmico feminista [...] e, sobretudo, da extensão de direitos homossexuais".

Jean Wyllys e Pabblo Vittar insultam a sociedade hetenormativa, por, na visão desta cultura, comportarem-se como sujeitos subversivos e, portanto, imorais aos padrões historicamente estabelecidos. Fou- 
cault (2004), no entanto, acredita que é preciso haver uma defesa dos direitos sexuais, assim como também afirmar uma identidade. Embora não se trate disto aqui, a discussão a respeito da homossexualidade ou dos sujeitos desviantes (drag queens, travestis, transexuais etc) é imperativo, pois é uma via que explica a fabricação de fake news que versa sobre estes sujeitos.

Antes disso, cabe ressaltar que, para Foucault (2018), a sexualidade é um dispositivo histórico, construído socialmente, dado que sua formação se dá através da história, a partir de "múltiplos discursos sobre o sexo: discursos que regulam, que normatizam, que instauram saberes, que produzem 'verdades'”' (LOURO, 2000, p. 06). Este dispositivo, na concepção de Foucault, demarca

um conjunto heterogêneo que engloba discursos, instituições, organizações arquitetônicas, decisões regulamentares, leis, medidas administrativas, enunciados científicos, proposições filosóficas, morais, filantrópicas. Em sua, o dito e não dito são os elementos do dispositivo. 0 dispositivo é a rede que se pode estabelecer entre estes elementos (FOUCAULT, 2017, p. 244).

A homossexualidade, pensada assim, ocupou o lugar de reclusão social, haja vista que, no decorrer do século XIX, na literatura, no campo jurídico e psiquiátrico, instituiuse o selo de "perversidade" e controle. No entanto, sabendo que o poder é uma rede de confronto, a homossexualidade reagiu ao cerceamento institucional, "pôs a falar por si mesma, a reivindicar sua legitimidade ou sua "naturalidade" e muitas vezes dentro do vocabulário e com as categorias pelas quais era desqualificada do ponto de vista médico" (FOUCAULT, 2018, p. 96).

Embora tenha se livrado do rótulo de doença mental em 1990, vozes intolerantes fazem ecoar discursos repressivos e nutridos de preconceitos. Os homossexuais e os demais sujeitos desviantes conquistaram espaço na sociedade brasileira, porém ainda persiste, notadamente durante o período do Governo Bolsonaro, posições ultraconservadoras, que buscam minar a participação destes sujeitos na vida pública. Igualmente, tentam posicioná-los como figuras abjetas, detestáveis. Esse comportamento, dentre muitos outros, desagua na fabricação de mentiras virtuais, uma vez que, publicizada uma ocorrência como esta em análise, provoca o asco e angaria apoio dos sujeitos que se intitulam defensores da criança e da família.

Isso, por outro lado, coincide com a afirmação de Foucault (2018) de que a sexualidade não cessa de produzir discursos generalizados. De acordo com o filósofo francês, "criaram-se em todo canto incitações a falar; em toda parte, dispositivos para ouvir e registrar, procedimentos para observar, interrogar, formular" (FOUCAULT, 2018, p. 34). Assim, Foucault (2018) acredita que talvez, em nenhum outro tipo de sociedade, falouse tanto sobre sexo - por conseguinte, sexualidade - como a nossa. Ora, vejamos que, ao ser produzidos fake news com o objetivo de suscitar o cuidado com as crianças em contato com sujeitos desviantes, produz-se, também, discursos sobre a sexualidade.

Por fim, voltando o olhar para as agências de checagem como o E-farsas, flagramos que estas se insurgem como um guardião da verdade, pois institui o verdadeiro, dado a vontade de verdade que é impelida por elas. No jogo de definição entre o verdadeiro e o falso, as agências de checagem constituemse como principal mediador na conjuntura contemporânea, produzindo, dessa forma, discursos verídicos. De acordo com Silva, Albuquerque e Veloso (2019), trata-se de uma atividade jornalística pós-noticiosa, 
pois os objetivos de tais agências não é produzir uma notícia em primeira mão, mas averiguar dados e informações antes noticiados, seja por agentes, assessorias ou pela própria imprensa para, em seguida, validar ou reprovar o fato. Assim, tal característica faz com que o alcance da notícia da agência de checagem não tenha tanta repercussão junto ao público quanto à informação precedente, fazendo com que esse (des)encontro de verdades seja intensificado.

\section{Para efeito de fim}

Neste texto, analisamos o funcionamento de uma moral cristã que subjaz à emergência de discursos sobre sexualidade na escola a partir de notícias falsas veiculadas nas redes sociais digitais. 0 exercício de três notícias falsas checadas pelo site E-farsas permitiu-nos entrever que há a construção do ambiente escolar como um espaço potencialmente nocivo para a inocência da criança, haja vista que dele brotam valores e práticas consideradas agressivas para a moral cristã. Nessa ótica, o repúdio às condutas homoafetivas, travestidas em docentes doutrinadores de ideologias de esquerda e à condenação da presença de um ensino de práticas sexuais concebidas como desviantes com sujeitos conhecidos da mídia, realçam esse quadro de pavor pintado pelas posições discursivas que enunciam nas notícias falsas.

Desse modo, desde o "kit gay" propalado por Bolsonaro ainda quando era deputado até à performance pornográfica de uma professora de esquerda e à turnê de Jean Wyllys e Pablo Vittar em escolas do Brasil, constatamos como o discurso, conforme lembrava Foucault (2009), articula-se com o desejo e o poder. No caso da relação entre sexualidade e a escola, subsiste uma guerrilha de verdades entre as notícias falsas que dizem o que nelas querem acreditar e as agências de checagem que buscam desmontar esses jáditos a partir do recurso à curadoria da prática discursiva jornalística. Ainda que não haja uma remissão direta aos elementos da religião cristã no esteio das materialidades estudadas, por meio de excertos bíblicos ou exortações, é dessa moral que se trata, pois ela sustenta os modos de governar localizados na contracorrente de todos os avanços de política de direitos sexuais e das minorias. Foi a partir de tal moral que tantas outras fake news impulsionaram a vitória eleitoral de um candidato que se dizia lutar por uma dada concepção família e pela preservação de valores considerados tradicionais.

\section{Referências}

ALMEIDA, Ronaldo de. Bolsonaro presidente: conservadorismo, evangelismo e crise brasileira. Novos Estud. CEBRAP, São Paulo, v. 38, n.1, p. 185-213, jan./abr. 2019. Disponível em: <https://www.scielo.br/pdf/nec/v38n1/19805403-nec-38-01-185.pdf>. Acesso em: 09 jan. 2020.

BRANDÃO, Elaine Reis; LOPES, Rebeca Faray Ferreira. "Não é competência do professor ser sexólogo": 0 debate público sobre gênero e sexualidade no Plano Nacional de Educação. Civitas. Porto Alegre, v. 18, n.1, p. 100-123, jan./abr. 2018.

CANDIOTTO, Cesar. A genealogia da ética de Michel Foucault. Educação e Filosofia. v. 27, n. 53, jan-jun, Uberlândia, 2013.

CALDAS, Camilo Onoda Luiz; CALDAS, Pedro Neri Luiz. Estado, democracia e tecnologia: conflitos políticos e vulnerabilidade no big-data, das fake news e das shistorms, Perspect. ciênc. inf. Belo Horizonte, v.24, n.2, p. 196-220, abr./jun. 2019.

FARIAS, Daniel Costa. A ética dos antigos e o questionamento de nossa atualidade: o problema da moral em Michel Foucault. Problemata: Rt. Intern. Fil. v. 6, n. 3, 2015.

FERRARI, Pollyana. Como sair das bolhas. São 
Paulo: EDUC/Fortaleza: Armazém da Cultura, 2018.

FOUCAULT, Michel. História da sexualidade II: o uso dos prazeres. Rio de Janeiro: Edições Graal, 1984.

FOUCAULT, Michel. 0 sujeito e o poder. In: RABINOW, Paul; DREYFUS, Hubert L. Foucault: uma trajetória filosófica para além do estruturalismo e da hermenêutica. Trad. Vera Porto Carrero. Rio de Janeiro: Forense Universitária, 1995, p. 231-250.

FOUCAULT, Michel. Michel Foucault, uma entrevista: sexo, poder e a política da identidade. Verve - Revista do Nu-Sol. 5: 2004. p. 260-277.

FOUCAULT, Michel. Sexualidade e Poder. In: Ditos e Escritos V: Ética, sexualidade e política. Rio de Janeiro: Forense Universitária, 2006.

FOUCAULT, Michel. 0 Uso dos Prazeres e as Técnicas de Si. In: Ditos e Escritos V: Ética, sexualidade e política. Rio de Janeiro: Forense Universitária, 2006.

FOUCAULT, Michel. A ordem do discurso. 19. ed. Ed. M. J. Marcionilo. São Paulo: Edições Loyola, 2009.

FOUCAULT, Michel. Vigiar e Punir: nascimento da prisão. Tradução de Raquel Ramalhete. 42. ed. Petrópolis/RJ: Vozes, 2014.

FOUCAULT, Michel. Subjetividade e Verdade: curso no Collége de France (1980-1981). São Paulo: Editora Martins Fontes, 2016.

FOUCAULT, Michel. Poder-corpo. In: FOUCAULT, Michel. Microfísica do Poder. Rio 5. ed. Rio de
Janeiro: Paz e Terra, 2017.

FOUCAULT, Michel. Sobre a prisão. In: FOUCAULT, Michel. Microfísica do Poder. 5 ed. Rio de Janeiro: Paz e Terra, 2017.

FOUCAUL, Michel. História da sexualidade I: a vontade de saber. Tradução de Maria Thereza da Costa Albuquerque e J. A. Guilhon Albuquerque. 7 ed. Rio de Janeiro/São Paulo: Paz e Terra, 2018.

MACHADO, Maria das Dores Campos. 0 discurso cristão sobre a "ideologia de gênero". Revista de Estudos Feministas. Florianópolis, v. 26, n.2, p. 1-18, 2018.

MISKOLCI, Richard; CAMPANA, Maximiliano. "Ideologia de gênero": notas para a genealogia de um pânico moral contemporâneo. Sociedade e Estado. vol.32, n. 3, Brasília, Departamento e Programa de Pós- Graduação em Sociologia, 2017, pp.723-745.

MISKOLCI, Richard. Exorcizando um fantasma: os interesses por trás do combate à "ideologia de gênero". Cad. Pagu. Campinas, n. 53, p. 1-14, 2018.

SANTAELLA, Lúcia. A pós-verdade é verdadeira ou falsa? Barueri/SP: Estação das Letras e Cores, 2018.

SILVA, Mayara Carla Dantas da; ALBUQUERQUE, Maria Elizabeth Baltar Carneiro de; VELOSO, Maria do Socorro Furtado. Representação da informação noticiosa pelas agências de fact-checking: do acesso de informação ao excesso de desinformação. Revista Brasileira de Biblioteconomia e Informação. São Paulo, v. 15, n.2, p. 410-426, 2019.

Recebido em: 12/05/2020 Aceito em: 18/06/2020 